\title{
IMPORTÂNCIA DAS OFICINAS DE TREINAMENTO PARA OS MILITARES DO CORPO DE BOMBEIROS MILITAR
}

\section{IMPORTANCE OF TRAINING WORKSHOPS FOR MILITARY FIRE OFFICERS}

Leonardo Menezes dos Santos ${ }^{1}$

RESUMO: O presente artigo analisa a possibilidade de implantação de oficinas de treinamento para os militares do Corpo de Bombeiros Militar de Roraima (CBMRR). Para chegar a essa proposta, foram observadas pelo pesquisador algumas falhas na execução de procedimentos básicos ao atendimento de ocorrências do serviço operacional do CBMRR, tais como: a dúvida no papel a ser desempenhado por cada membro que compõe a equipe de salvamento que é escalada diariamente. Alguns militares estariam sobrepondo a função de outros membros da equipe e em outros casos, integrantes que deixam de exercer a sua função corretamente na cena da ocorrência. Também foi observada a deficiente manutenção dos materiais utilizados pelos militares no serviço, gerando desgaste prematuro dos equipamentos, além de atendimento duvidosos de ocorrência via número telefônico 193. Com isso foi estudado a eficiência de se implantar uma de treinamento continuado, através de oficinas de áreas essenciais ao desenvolvimento da atuação dos militares da corporação, seria uma opção para diminuir as falhas ocorridas.

Palavras-chave: Treinamento, equipe, oficinas.
ABSTRACT: This article analyzes the possibility of implementing training workshops for the military of the Military Fire Brigade of Roraima (CBMRR). In order to arrive at this proposal, the researcher observed some flaws in the execution of basic procedures to attend to occurrences of the operational service of the CBMRR, such as: the doubt in the role to be played by each member that makes up the rescue team that climbs daily. Some military personnel would be superimposing the function of other members of the team and in other cases, members who fail to perform their duties correctly at the scene of the occurrence. It was also observed the deficient maintenance of the materials used by the military in the service, generating premature wear of the equipment, as well as doubtful attendance of occurrence via telephone number 193. With this, the efficiency of implementing a continuous training was studied through field workshops essential to the development of the corporation's military operations, would be an option to reduce the failures that occurred.

Keywords: Training, team, workshops.

1 Mestrando em Segurança Pública, Direitos Humanos e Cidadania pela Universidade Estadual de Roraima leopelopes23@gmail.com 


\section{INTRODUÇÃO}

O aumento populacional da cidade de Boa Vista, aliado à crescente migração de venezuelanos para o estado de Roraima, têm exigido cada vez mais do Corpo de Bombeiros Militar de Roraima (CBMRR). Para se ter uma ideia do rápido crescimento populacional de Roraima, segundo dados da (Polícia Federal, 2019), somente no ano de 2017, o estado de Roraima recebeu 15.955 pedidos de refúgio de imigrantes venezuelanos. No entanto, o número apresentado pelo Alto Comissariado das Nações Unidas refere-se apenas aos números oficiais da Polícia Federal. Porém, é perceptível para quem vive em Roraima que a quantidade de refugiados que vivem atualmente no nosso estado é ainda maior, pelo fato de muitos venezuelanos não registrarem suas permanências oficialmente as autoridades brasileiras.

Outro dado importante que prova esse aumento demográfico no estado é o de (IBGE, 2019), que estima, em 2018, no estado de Roraima, uma população de 576.568 habitantes. Aumentando em oito anos mais de cem mil habitantes conforme o censo oficial (IBGE, 2019) que registra 450.479 habitantes do ano de 2010.

Naturalmente, com o aumento populacional, o número de ocorrências na capital aumentou significativamente, exigindo uma maior atuação dos militares que exercem as suas atividades nas unidades operacionais na capital. Nesse sentido, o artigo analisa a eficiência das oficinas de treinamento para os militares do Corpo de Bombeiros Militar de Roraima (CBMRR), como uma maneira de solucionar problemas identificados no cotidiano da Corporação.

Para que a implantação de uma rotina de oficinas seja eficiente para a realidade da tropa, foram levantadas as reais necessidades de treinamento para a Corporação. Com isso, o pesquisador dividiu as oficinas em três grupos: Oficiais, Subtenentes e Sargentos, e por fim Soldados. A motivação para essa separação de público se dá pelo fato de cada militar tem o seu papel específico dentro de uma atividade de salvamento.

\section{COMPOSIÇÃO DA EQUIPE DE SALVAMENTO}

Para entender o motivo pelo qual as oficinas de treinamento foram divididas para grupos distintos dentro da Corporação, faz-se necessário entender a função de cada integrante do Equipe de Salvamento. Em primeiro lugar vale ressaltar que essa equipe escalada diariamente para atuar no atendimento de ocorrências é chamada de Trem de Socorro. Essa equipe é composta pelas seguintes funções:

Coordenador de Operações: desempenhada por um Oficial;

Comandante do Socorro: desempenhada pro um Oficial;

Ambulância de Resgate: comandada por um Subtenente ou Sargento e composta por mais três Cabos ou Soldados; e

Viatura de Salvamento: comandada por um Subtenente ou Sargento e composta por mais três Cabos ou Soldados.

Dentro da equipe de salvamento, que atua no atendimento de ocorrências, os membros têm as seguintes atribuições: O Coordenador de Operações é o Oficial mais antigo escalado no dia. Ele permanece 24 horas na Central de Operações, onde são recebidas as chamadas telefônicas do número 193. Sendo assim, ele fica responsável por auxiliar o Comandante do Socorro nos atendimentos das ocorrências., tendo a função de definir, junto com os militares da central telefônica, quais viaturas atenderam as ocorrências, solicitar apoio de outros órgãos que possivelmente sejam necessários para solucionar um atendimento, como por exemplo: caminhões pipa da companhia 
estadual de águas e esgotos, equipes da companhia de energia elétrica, imprensa e etc.

Já o Comandante do Socorro é o responsável por toda a equipe escalada no dia, atuando como gestor do serviço operacional. Sendo ele responsável por coordenar as operações de salvamento, buscando manter a segurança da equipe e fazer o elo de ligação com outras instituições que venham por ventura auxiliar nos atendimentos, como por exemplo Polícia Militar, SAMU, Detran, Polícia Rodoviária Federal etc. Com isso, pode-se notar que o Oficial tem um papel menos atuante no contato direto com as vítimas, tendo que aplicar estratégias diferentes dos demais militares do Trem de Socorro.

Os Subtenentes e Sargentos são os militares que comandam as guarnições que compõem o trem de socorro, como: ambulância, viatura de salvamento e viatura de combate a incêndio. São militares incumbidos de comandar os militares que integram as suas viaturas e contabilizam mais tempo de serviço na Corporação. Por isso, possuem mais experiência operacional pelo fato de terem vivenciado mais ocorrências que os Cabos e Soldados. Eles, além de atuarem diretamente no salvamento, são responsáveis por manter o Comandante do Socorro informado sobre as ações que estão sendo realizadas no salvamento e, administrar, em conjunto com os comandantes das outras viaturas, o atendimento da ocorrência.

Por fim, os Cabos e Soldados são os militares que atuam diretamente no atendimento das vítimas da ocorrência. Esses bombeiros têm, na maioria das vezes, menos de tempo de serviço na Corporação e por isso possuem pouca experiência para gerenciar uma equipe. Suas funções limitamse a aplicação dos métodos de salvamento aprendidos e seus cursos de formação.

\section{OBJETIVOS}

Foram analisadas cinco problemáticas identificadas pelo autor, sendo elas:

Dirimir a dúvida no papel a ser desempenhado por cada membro que compõe a equipe de salvamento que é escalada diariamente;

Acabar com a sobreposição da função de alguns militares frente a outros membros da equipe durante $\mathrm{o}$ atendimento de uma ocorrência;

Ressaltar o papel de cada integrante no cenário da ocorrência, uma vez que foi observado que alguns militares deixam de exercer a sua função corretamente;

Instruir acerca da correta utilização dos materiais utilizados pelo CBMRR, visando o aumento de sua vida útil; e

Otimizar o atendimento de ocorrência via número telefônico 193.

\section{METODOLOGIA}

A pesquisa, quanto a sua natureza, é aplicada no sentido de solucionar alguns problemas identificados pelo pesquisador no serviço operacional do Corpo de Bombeiros Militar de Roraima, na cidade de Boa Vista. Para Marconi e Lakatos (2010, p. 17): ”A Metodologia Científica, mais do que uma disciplina, significa introduzir o discente no mundo dos procedimentos sistemáticos e racionais, base da formação tanto do estudioso quanto do profissional, pois ambos atuam, além da prática, no mundo das ideias."

Thiollent (2014, p. 207-216), afirma que: "a metodologia é disciplina relacionada com a epistemologia e a filosofia da ciência, tendo por função analisar e avaliar os diversos métodos disponíveis, além de ser considerada como o modo de conduzir a pesquisa”.

$\begin{array}{cccc}\text { O tema } & \text { "PROPOSTA } & \text { DE } \\ \text { IMPLANTAÇÃO } & \text { DE } & \text { OFICINAS } & \text { DE }\end{array}$ 
INSTRUÇÃO PARA O EFETIVO DO CORPO DE BOMBEIROS MILITAR NO ESTADO DE RORAIMA", escolhido por esse pesquisador tem o objetivo de observar a eficiência de se implantar oficinas de instrução para os militares da Corporação.

A pesquisa tem abordagem qualitativa e quantitativa, uma vez que mesmo que seja baseada em pontos de vista particulares, para um entendimento do problema a ser debatido, foram utilizados questionários a fim de subsidiar a análise feita nos resultados obtidos nas instruções ministradas ao longo do estudo.

Quanto aos objetivos, a pesquisa qualifica-se como descritiva uma vez que o levantamento de dados forneceu números necessários para que se estabeleça relações entre variáveis. Foram utilizados questionários fechados como instrumento de coleta de dados. Nessa abordagem o objetivo do pesquisador é traduzir em números as opiniões e o grau de satisfação do universo estudado em relação ao problema proposto.

Para que essa coleta de dados fosse possível, o pesquisador efetuou uma pesquisa de campo. E, segundo Gil (2002), a pesquisa de campo "é um estudo profundo e exaustivo de um ou poucos objetos, de maneira que permita seu amplo e detalhado conhecimento".

Para a conclusão desta pesquisa, as informações foram obtidas através de questionário de 09 (nove) perguntas relacionadas ao assunto estudado, aplicado aos alunos do Curso de Habilitação de Oficiais do Corpo de Bombeiros Militar de Roraima.

\section{TREINAMENTO}

Nenhum profissional pode ficar estagnado em sua formação profissional, uma vez que esta nutre o indivíduo com um conhecimento mínimo necessário para a prática do exercício da profissão. Conforme cita (CHIAVENATO, 2011 p. 368),

Treinamento é a experiência aprendida que
produz uma mudança relativamente
permanente em um indivíduo e que melhora
sua capacidade de desempenhar o cargo. O
treinamento pode envolver uma mudança de
habilidades, conhecimento, atitudes ou
comportamento. Isso significa mudar aquilo
que os empregados conhecem, como eles
trabalham, suas atitudes perante o seu
trabalho ou suas interações com os colegas
ou supervisor.

Na sequência da formação profissional, deve existir um treinamento para que o indivíduo possa:

1) Entender, na prática, aquilo que ele aprendeu na teoria;

2) Interagir com o novo grupo em que ele foi inserido, entendo a sua função dentro daquele corpo;

3) Atualizar aquele grupo com novas teorias que o indivíduo acabou de adquirir e que vai ser útil para a otimização do trabalho;

4) Adaptar-se à política da Corporação; e

5) Entender o relacionamento da organização com o cliente.

É interessante distinguir dois tipos de treinamento. $\mathrm{O}$ treinamento de inserção e o treinamento de adestramento. O primeiro tem a finalidade de adaptar um novo indivíduo ao grupo que ele está sendo admitido.

Souza (1993) refere, também, que a educação continuada nas instituições deve acompanhar o profissional desde a sua inserção, fazendo-o adaptar-se à mesma e dando-lhe condições de prosseguir na sua performance profissional, mantendo sua prática relevante e orientada, valorizando o seu fazer diário e transformando-o em trabalho de comunicação científica

Além disso, o responsável pela gestão de pessoas da organização deve se preocupar com o adestramento constante de seus subordinados para a busca da otimização do 
trabalho, nesse segundo momento do treinamento, devem ser priorizados diferentes objetivos, que são eles:

1) Buscar informações e soluções para problemas do exercício da função;

2) Descobrir talentos para as áreas específicas;

3) Desenvolver ou aprimorar conceitos;

4) Aperfeiçoar a relação de trabalho dos indivíduos, fazendo com que todos conheçam a fundo suas atribuições, sem interferir no campo de atuação de outros funcionários;

5) Entender a prática da atividade para evitar lesões; e

6) Manusear de maneira correta os equipamentos que lhes são postos à disposição.

Leite e Pereira (1991), afirmam que a educação continuada é um processo que propicia novos conhecimentos, capacita o funcionário para a execução adequada do trabalho, preparando-o para futuras oportunidades de ascensão profissional, objetivando tanto o crescimento profissional quanto o pessoal.

Cabe ressaltar que o aprimoramento das organizações ocorre de maneira contínua ao longo da história das mesmas. Quando a necessidade de mudança é identificada, a organização elabora um plano de mudança de conduta ou de comportamento em suas políticas.

A partir daí, segundo (CHIAVENATO, 2011), um treinamento deve ser esquematizado para que essa mudança possa ocorrer de maneira eficiente, seguindo os seguintes passos:

1) Levantamento de necessidades de treinamento a serem satisfeitas;

2) Desenho do programa de treinamento;

3) Aplicação do programa de treinamento; e

4) Avaliação dos resultados do treinamento.

Wiersema-Treacy (2005) afirma que, existem três características que são comuns as empresas que lideram 0 mercado. Centralização de um foco em um ponto único valorizado pelos clientes, melhoria contínua naquilo que elas oferecem aos clientes e a formação e treinamento dos funcionários voltados para a meta determinada.

\section{ENDOMARKETING}

Empresas mais lucrativas do cenário mundial, como McDonald's, Johnson \& Johnson, Hewllet-Packard, Toyota e Ford fundamentam uma estrutura operacional de forma que o produto/serviço chegue ao cliente da maneira que ele exige, com o valor agregado desejado por eles. E essas empresas focam nos seus colaboradores a importância do sucesso na ponta da linha. A esse tipo de estratégia, dá-se o nome de Endomarketing. O Principal objetivo do endomarketing é tirar o máximo dos colaboradores em prol do produto ou serviço oferecido pela empresa. Bekin (1995), salienta três pilares para que o endomarketing obtenha sucesso:

1) O cliente só pode ser fidelizado com a excelência do serviço;

2) Os colaboradores são os primeiros clientes da empresa. E essa deve dirigir total valorização a esses clientes; e

3) Um serviço só consegue chegar a um padrão ótimo com o envolvimento de todos aqueles que participam de seus processos de fabricação.

$E$ porque pensar em endomarketing quando estamos analisando um Corpo de Bombeiros? Uma estrutura estatal e sem fins lucrativos.

Apesar de não ter fins lucrativos, é 
possível comparar a atividade do CBMRR a uma empresa. Onde os militares seriam os colaboradores, a população roraimense os clientes e o atendimento de ocorrências, o produto a ser oferecido.

Nesse ponto de vista, se faz importante a utilização da ferramenta do endomarketing na busca de melhores resultados no desempenho do militares do CBMRR. devem possuir condições físicas e psicológicas para poder prestar um excelente serviço a sociedade. Precisam estar motivados e atualizados para enfrentar as adversidades que a profissão bombeiro militar impõe no dia-a-dia.

\section{RESULTADOS PRELIMINARES}

\section{Gênero}

A amostra final conta com 42 respondentes, sem omissões a quaisquer respostas fechadas. Quanto ao gênero, a divisão dos respondentes foi de uma maioria de homens com 34 participantes, cerca de $77 \%$ e oito mulheres, cerca de $23 \%$ do total.

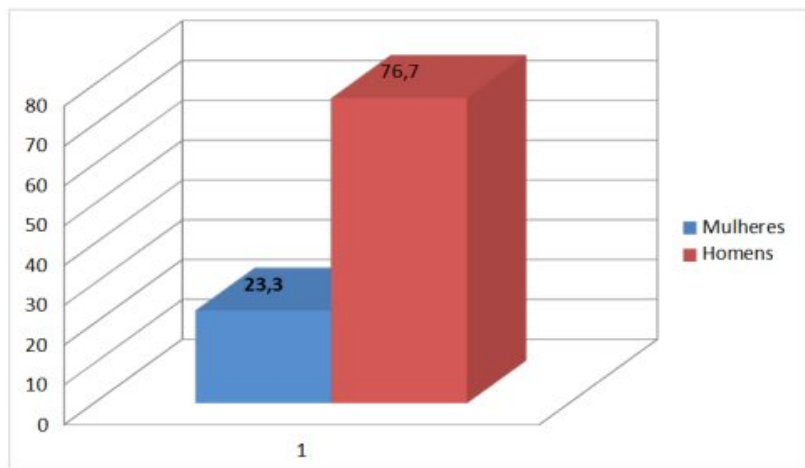

Fonte: próprio Autor

\section{Graduação}

A figura 02 mostra o público que foi objeto do estudo, nesse caso $100 \%$ dos militares avaliados sendo praças (Subtenentes, Sargentos, Cabos e Soldados). Militares que fazem parte da execução da atividade-fim da Corporação e tiram serviço nas equipes diárias de salvamento. A escolha se deu pelo fato de que a equipe de serviço diário ser composta por apenas dois oficiais, um Comandante do Socorro e um
Coordenador de Operações, e cerca de 70 praças.

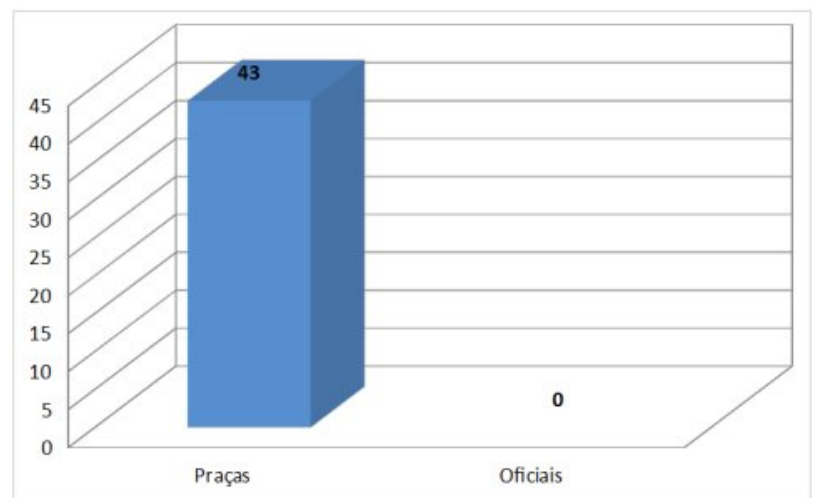

Fonte: próprio Autor

\section{Tempo de serviço na Corporação}

O público estudado tem tempo de serviço prestado ao CBMRR em diferentes níveis. O Importante em observar militares com tempo de efetivos serviços diferentes é que se tem um público com percepções diferentes em função de sua experiência vivida na Corporação ao longo dos anos. Onde 2,3\% dos entrevistados estão na Corporação há menos de 10 anos, $90,7 \%$ estão na Corporação há mais de 10 anos, porém há menos de 15 anos e por fim, $7 \%$ da população está no CBMRR há mais de 15 anos.

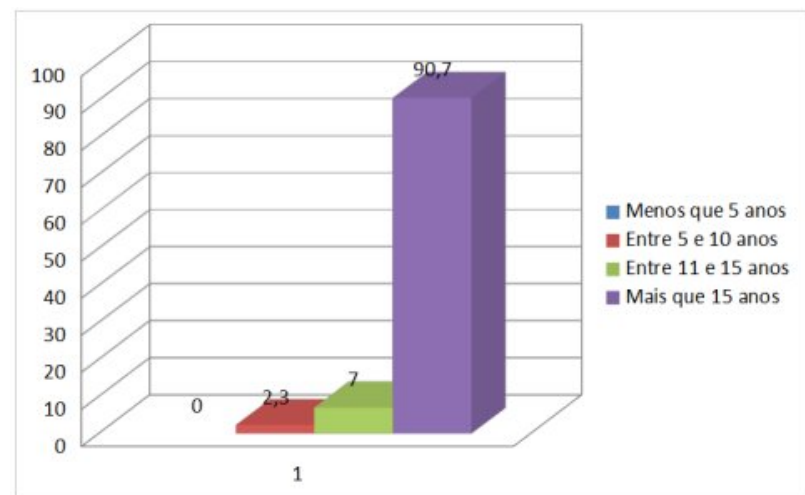

Fonte: próprio Autor

\section{Eficiência das oficinas}

Quanto a percepção dos avaliados em relação a serem submetidos constantemente a oficinas de treinamento escolhidas de acordo com a necessidade demandada, cerca de $90 \%$ dos entrevistados responderam que acham necessário o programa de oficinas de 
treinamento, enquanto $11,6 \%$ julgam ser irrelevante a prática de instruções para a Corporação

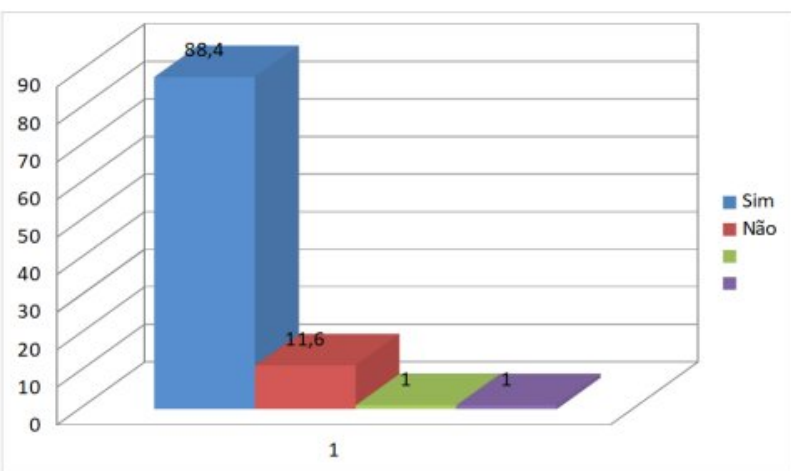

Fonte: próprio Autor

\section{Vida útil dos equipamentos}

Apesar de ter vários fatores que interferem na vida útil dos equipamentos utilizados pelo Corpo de Bombeiros, como por exemplo: exposição às intemperes do clima, correto armazenamento, transporte, qualidade de combustível utilizados em alguns equipamentos etc, a manutenção feita pelos militares do CBMRR é fundamental para aumentar a o bom estado de conservação desse material. Assim, 88.4\% acreditam que as oficinas de treinamento são essenciais para que o militar aprenda a conservar suas ferramentas de trabalho. Ao passo que, $11,6 \%$ entendem que as oficinas de treinamento não são eficientes no sentido de ajudar o militar a melhor preservar os equipamentos utilizados pelo Trem de Socorro.

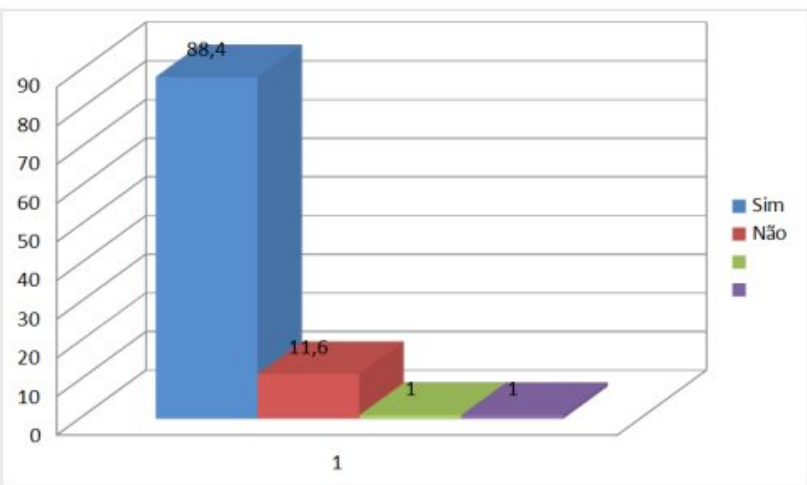

Fonte: próprio Autor

\section{Tempo Resposta}

Um dos objetivos da implantação das oficinas de treinamento é reduzir o tempo resposta no atendimento oferecido pelo número 193. Tempo resposta é o tempo gasto entre o momento em que $o$ atendente do Corpo de Bombeiros recebe o pedido de socorro da população pelo telefone e exato momento em que uma equipe chega ao local da ocorrência. Nesse quesito $72,1 \%$ dos respondentes acreditam que treinar a guarnição que trabalha nos atendimentos telefônicos oferecidos pelo número 193, através das oficinas seja relevante para reduzir o tempo resposta. Enquanto 27,9\% não observam a necessidade desse treinamento para alcançar esse objetivo.

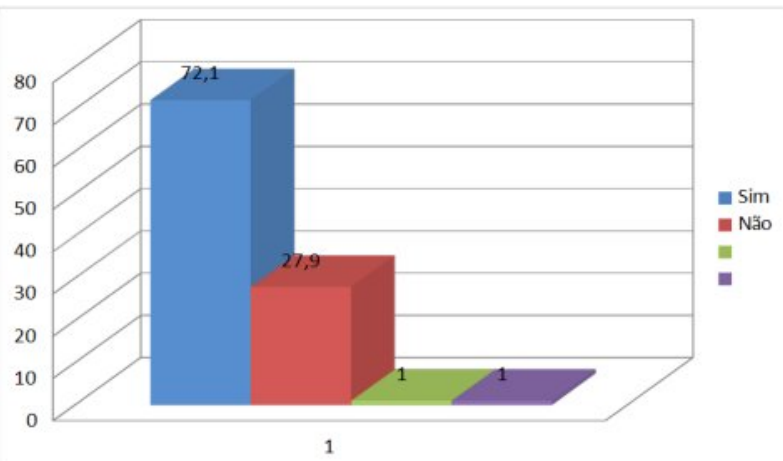

Fonte: próprio Autor

\section{Eficiência do atendimento 193}

Um dos objetivos da implantação das oficinas de treinamento é reduzir o tempo resposta no atendimento oferecido pelo número 193. Tempo resposta é o tempo gasto entre o momento em que o atendente do Corpo de Bombeiros recebe o pedido de socorro da população pelo telefone e exato momento em que uma equipe chega ao local da ocorrência. Nesse quesito $72,1 \%$ dos respondentes acreditam que treinar a guarnição que trabalha nos atendimentos telefônicos oferecidos pelo número 193, através das oficinas seja relevante para reduzir o tempo resposta. Enquanto 27,9\% não observam a necessidade desse treinamento para alcançar esse objetivo. 


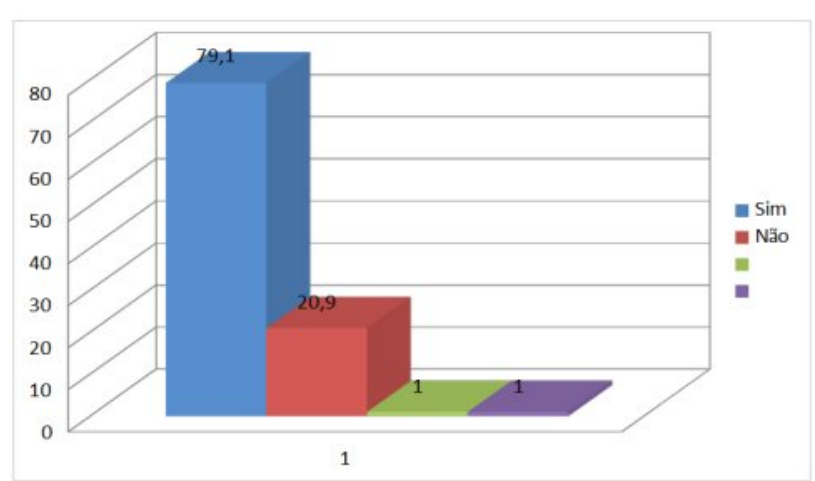

Fonte: próprio Autor

\section{Motivação}

Quanto a motivação, 83,7\% dos militares que responderam o questionário julgam que o processo de treinar as guarnições que atuam no trem de socorro é um incentivo motivacional. Mas, para 16,3\% as instruções não são suficientes para motivar a tropa.

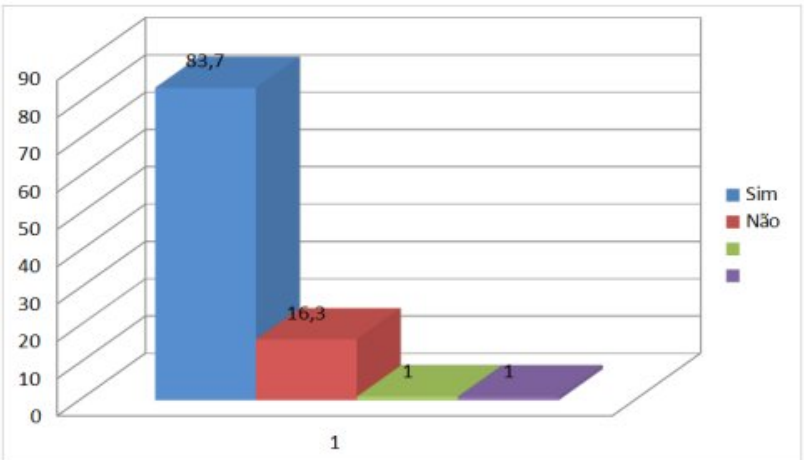

Fonte: próprio Autor

\section{Prioridade de treinamento}

Foi perguntado aos bombeiros entrevistados quais as áreas de atuação do Corpo de Bombeiros Militar de Roraima seriam mais importantes a serem treinadas pela Corporação. Eles escolheram 5 atividades que, segundo eles, são mais carentes de nivelamento e mais importantes a serem treinadas. Escolha 5 áreas de atuação do Corpo de Bombeiros que o(a) senhor(a) julga mais importante a serem treinadas atualmente:

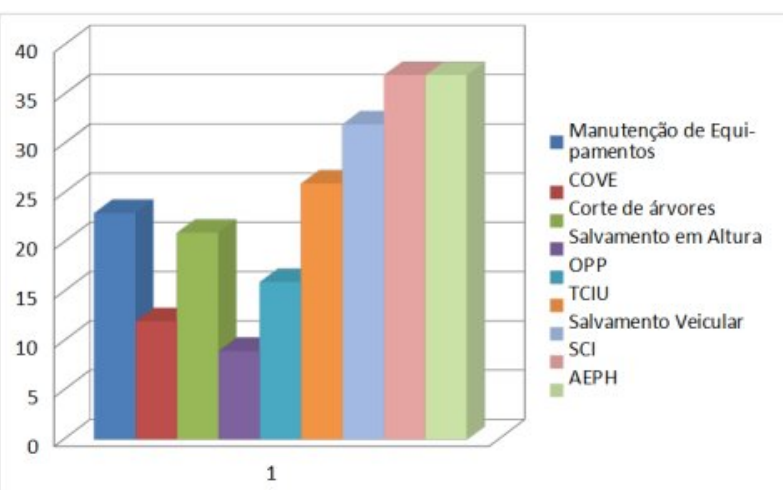

Fonte: próprio Autor

\section{CONSIDERAÇÕES FINAIS}

O objetivo deste trabalho foi avaliar a eficiência das oficinas de treinamento para os militares que atuam no $1^{\circ}$ Batalhão de Proteção Ambiental Bombeiro Militar do Corpo de Bombeiros Militar de Roraima, buscando junto ao público estudado suas opiniões em relação aos objetivos a serem alcançados pelas oficinas. Nesse sentido, buscou-se nivelar conceitos teóricos dos militares que participaram do estudo visando uma melhor atuação de cada membro da equipe de salvamento no trem do socorro, acabando com a sobreposição ou omissão de funções na hora do atendimento, uma melhor atuação da equipe atendem a população pelo número telefônico 193 e aperfeiçoar o uso dos equipamentos operacionais da Corporação.

Ficou evidente que as oficinas devem seguir a demanda da tropa no sentido de se trabalhar áreas que os próprios bombeiros julgam ser mais deficientes de treinamento e, principalmente, o calendário de execução desse projeto deve ser maleável. Como o Corpo de Bombeiros Militar de Roraima tem um efetivo muito reduzido, e a Corporação atende a diversos eventos no estado, tais como: incêndio florestal, serviço de guardavidas nos balneários da cidade, serviço de vistoria e perícia nos estabelecimentos comerciais da Capital e do Interior, fica inviável estabelecer um calendário fixo a ser seguido. A pesquisa mostrou que, em face a 
essas demandas, o ideal é que se estabeleça uma prioridade de áreas a ser treinadas e preparado um cronograma curto de atividades, para ser aplicado conforme a tropa tenha disponibilidade de tempo. Fixar um calendário torna-se inviável para o atual cenário vivenciado pela Corporação.

Com isso, são necessários treinamentos para a construção de um ambiente mais salutar de trabalho, para a redução de falhas no atendimento das ocorrências na cidade de Boa Vista, para que o risco de problemas e acidentes seja minimizado. Condições adequadas de trabalho são necessárias e devem ser exigidas para que a execução das atividades não traga riscos à saúde.

Como dever de todos e obrigação do Estado, a pesquisa mostra a necessidade urgente do comprometimento do Corpo de Bombeiros Militar de Roraima, em produzir e executar projetos de oficinas de treinamento, que sejam capazes de, em um primeiro momento reduzir os riscos de falha no atendimento, para que a população possa gozar de um serviço cada vez melhor.

\section{REFERÊNCIAS}

BEKIN, Saul F. Conversando sobre

Endomarketing. São Paulo: Makron Books,1995.

CHIAVENATO, I. Gestão de pessoas. 3 ed. rev. e atual. São Paulo: Elsevier, 2011.

GIL, A. C. Como elaborar projetos de

pesquisa. São Paulo: Atlas, 2002

INSTITUTO BRASILEIRO DE GEOGRAFIA E ESTATÍSTICA (IBGE).

Estatística demográfica do Estado de

Roraima. Disponível em:

https://www.ibge.gov.br/cidades-eestados/rr.html?. Acesso em: 20 jan 19

LEITE, M.M.J.; PEREIRA, L.L. Educação

continuada em enfermagem. In:

KURCGANT, P. Administração em

enfermagem. São Paulo: EPU, 1991. Cap.
12, p. 147-163.

MARCONI, M. de A.; LAKATOS, E. M. Fundamentos de Metodologia Científica. São Paulo: Atlas, 2010.

MINISTÉRIO DA JUSTIÇA(MJ). Refúgio em números - $3^{\text {a }}$ Edição. Disponível em: https://www.acnur.org/portugues/wpcontent/uploads/2018/04/refugio-emnumeros_1104.pdf. Acesso em: 10 out. 2015.

SOUZA, M.B.B. de. A gênese da educação continuada em enfermagem e seu percurso histórico no HCRP/USP-19561986. Ribeirão Preto, 1993. 203p.

Dissertação (Mestrado em Enfermagem) Escola de Enfermagem de Ribeirão Preto, Universidade de São Paulo

THIOLLENT, Michel. Pesquisa-ação, formação de professores e diversidade. Acta Scientiarum. Human and Social Sciences , v. 36, p. 207-216, 2014.

TREACY, M., WIERSEMA, F. A disciplina dos líderes do Mercado. $3^{\text {a }}$ ed. Rio de Janeiro: Rocco, 2005. 